\title{
The Golgi Apparatus: Morphology and Function with Recent Facts
}

(D) Mukaddes EŞREFOĞLU

Bezmialem University Faculty of Medicine, Department of Basic Medical Sciences Department of Histology and Embryology, İstanbul, Turkey

\begin{abstract}
At the center of the secretory pathway, the Golgi complex ensures correct processing and sorting of cargos towards their final destination sites which are the cytoplasm, plasma membrane, and endosome-lysosome system. Recent technological developments have discovered new morphological and functional charcteristics of the Golgi apparatus. In this review, I emphasize that the Golgi apparatus is not a stable organelle instead a highly dynamic organelle changing its morphological and functional characteristics in different physiological and pathological conditions. It is not composed of a simple discontinuous parallel stacks but is composed of various domains such as cis-Golgi network, transGolgi network, and intercisternal network including various coated vesicles, vacuoles and tubules. Furthermore, the Golgi apparatus is not only involved in the secretory pathway, but also involved in the storage of $\mathrm{Ca}^{2+}$ very likely to smooth endoplasmic reticulum. Additionally, the Golgi apparatus might serve as a microtubule organizing center which is especially important to participate in Golgi reassembly after cell division.
\end{abstract}

Keywords: Golgi apparatus, secretory pathway, ER-Golgi intermediate compartment, microtubule organizing center

\section{Introduction}

\section{The Importance of the Golgi Apparatus}

The eukaryotic cells have various membraneous and nonmembranous organelles within their cytoplasm. According to the scientists, the Golgi apparatus (GA) is commonly considered as the most important organelle. According to my opinion it is also the most suprising and exciting oragenelle. Although it has been detected many years ago, several unexpected morphological or functional features of the GA are still emerging. This is why I am especially interested in the GA in this review.

\section{The Morphology of the Golgi Apparatus}

The Arrangement of the Golgi Apparatus: The GA consists of compact stacks of membrane limited sacs or cisternae, dilated at the periphery, along with many vesicles involved in vesicular transport between the sacs (1) (Figure 1). Its main functions are to modify and sort proteins and lipids that are transported through this organelle en route to their final destinations, such as the extracellular medium, plasma membrane and the endosomal/ lysosomal compartments (2). In mammalian tissue culture cells, it consists of flattened membrane-bound compartments, called "cisternae". The cisternae form Golgi stacks (one Golgi stack is formed via grouping of a number of cisternae in a parallel manner), themselves interconnected by lateral tubules to form the Golgi ribbon (Figure 2). The Golgi ribbon displays a juxtanuclear localisation next to the microtubule organising center (3). The Golgi ribbon is intact in interphase and dispersed into tubularreticular and vesicular elements in mitosis (4). Additionally, in the absence of intra-Golgi transport, the Golgi ribbon is partially fragmented (5). Both Golgi stacks and ribbon are polarised with an entry (cis) face, where cargo molecules synthesised in the endoplasmic reticulum (ER) reach the Golgi, and an exit (trans) face, where they leave for their downstream locations (3). Up
Address for Correspondence: Mukaddes Eşrefoğlu, Bezmialem University Faculty of Medicine, Department of Basic Medical Sciences Department of Histology and Embryology, İstanbul, Turkey E-mail: mesrefoglu@bezmialem.edu.tr ORCID ID: orcid.org/ 0000-0003-3380-1480
Received: 24.09 .2018

Accepted: 12.02 .2019

Cite this article as: Eşrefoğlu M. The Golgi Apparatus: Morphology and Function with Recent Facts. Bezmialem Science 2019;7(4):331-8. 
to 100 Golgi stacks, each composed of five to eight flattened cisternae are connected by membranous tubular bridges, called the noncompact zones, and are positioned next to the centrosome (6). Golgins are peripheral membrane proteins that are proposed to maintain this 3D arrangement of Golgi membranes by providing a structural skeleton (7). Golgin-mediated tethering is important for maintaining optimum Golgi function required for correct cargo processing and trafficking, which in the context of a whole organism is important for normal development and physiology (8). Golgi ribbon organization also depends on an intact microtubule and actin cytoskeleton, specialized cytoskeleton-based motors and membrane input from the ER $(5,9)$. The cisternae stacking might be related with the accuracy of protein glycosylation but not with the protein transport (10). The dispersed Golgi cisternae of $S$. cerevisiae are able to secrete efficiently (11). Interestingly, a recent study showed that loss of Golgi stacking leads to an increased rate of protein transport but defects in glycosylation (12). It has been suggested that the Golgi ribbon allows lateral diffusion of glycosylation enzymes between cisternae of adjacent stacks and also facilitating optimal processing of proteins transisting through the GA (13). It is possible that one part of the ribbon is in contact to several restricted organelles or moieties, such as localised mRNAs, and that some of stacks

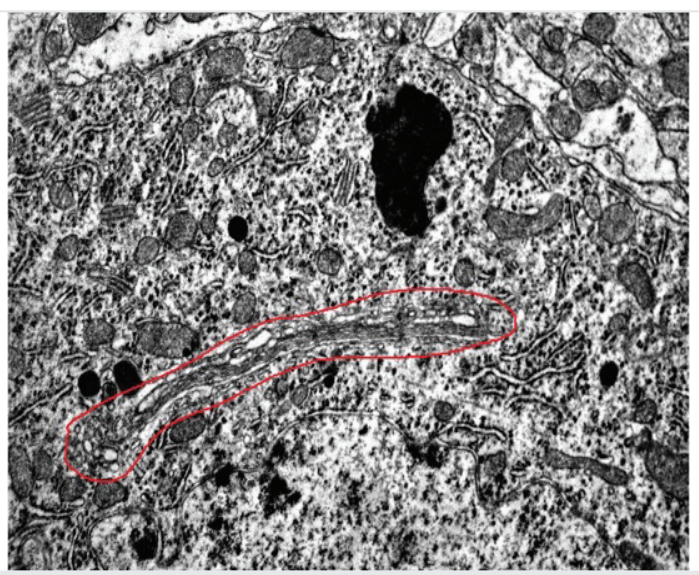

Figure 1. The Golgi apparatus (in red line) within the cytoplasm of a cerebellar neuron is observed. Note the vesicles around the Golgi apparatus. X 10.000

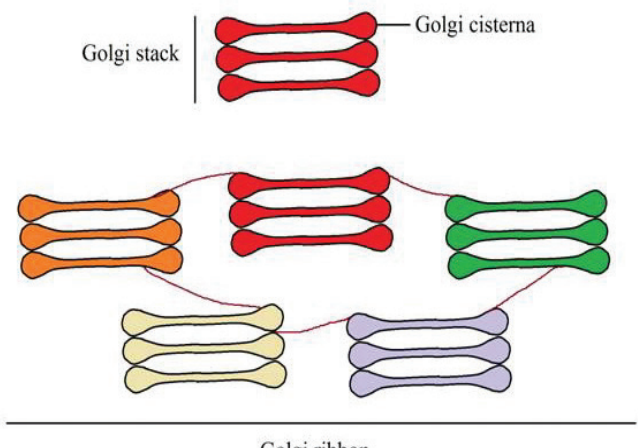

Golgi ribbon

Figure 2. The formation of the Golgi ribbon is shown (drawn by the author herself) of the ribbon mediate transport of the encoded proteins (14). Taken together, these data show that the integrity of the Golgi stacks and cisternae is not needed for competently carrying the bulk of proteins to the cell membrane.

The Biogenesis of the Golgi Apparatus: Two opposing models have been suggested about the biogenesis of the GA; the Golgi matrix and the de novo Golgi formation. According to the first model, the GA is an autonomous organelle built on a pre-existing template which is proposed to be a Golgi matrix containing some Golgi matrix proteins and F-actin $(15,16)$. These proteins including p115, GM130 might take part in building or maintaining Golgi stack architecture and ribbon formation $(14,16)$. In the de novo Golgi formation model, the GA is considered as an ER outgrowth. The membrane at ER exit sites carries all the necessary molecular information to trigger the building of a GA by a mechanism of self-organization (17). In this model, it is the structural integrity of ER exit sites and anterograde transport that are crucial for Golgi stack formation (14). It is not clear whether the membrane flux from the ER is the major determinant of the formation and reorganization of the GA or the GA exhibits considerable anatomy.

It is a fact that the GA is a dynamic organelle. During the cell proliferation, first sign of the Golgi ribbon disintegration is the disconnection to yield seperate Golgi stacks (disruption of the intermembraneous bridges) (18). Then, stacks are transferred into tubular-reticular membranes, called "Golgi blobs", which are dispersed throughout the cytoplasm. The "Golgi blobs" are then broken down to yield the "Golgi haze", which is composed of small dispersed vesicles (19). Postmitotic Golgi reassembly begins in telophase and involves the formation of two smaller Golgi ribbons that eventually coalesce (20).

The Domains of the Golgi Apparatus: The GA has two faces. One of them which is convex one is the forming face (or input face or -cis face; receiving department) which receives the proteins in transport vesicles from the adjacent cisternae of the rough ER (RER). The opposite concave face is the maturing face (or trans face; shipping department) which releases the modified, concentrated, sorted, packaged or labelled product into the cytoplasm (1). The most salient hallmark of Golgi structure is the presence of multiple membranous compartments, differentiated into cis, medial, and trans-Golgi, and organized into flattened stacks, which facilitates many key Golgi functions in mammalian cells (21). Morphological studies suggest that cisternae form at the cis face of the GA, progress through the stack to the trans face, and ultimately dissipate (22). Indeed, detailed studies provided strong evidence that procollagen containing cisternae progress from the cis to the trans side of the stack (23). Because trans cisternae have a different resident protein composition than cis cisternae, the implication is that cis cisternae mature into trans cisternae (11). At the cis face of the Golgi ribbon, proteins and lipids are delivered from the ER via vesicular-tubular clusters (VTCs), which dock at the cis-cisterna (24). Here, they either fuse with a preexisting cis-cisterna, or use the existing cis-cisterna as a template for the formation of a new cisterna (25). VTCs alternatively are referred to as the 
ERGIC (ER-Golgi intermediate compartment) or the cis-Golgi network (26). The formation of new cisternae at the cis-Golgi is coordinated with the fragmentation and consumption of the trans-Golgi (27). Trans face [trans Golgi network (TGN)] is the compartment where proteins and lipids are sorted and exit the GA. The proteins delivered from the GA may more or less temporarily remain within the cytoplasmic matrix (secretory proteins, glycoproteins) or integrate in apical and basolateral plasma membrane (integral or peripheral membrane proteins) or enter into the endosomes or lysosomes (lysosomal proteins) (Figure 3). The GA is especially well-developed and active in cells that secrete protein/glycoprotein by exocytosis (both for exocrine and endocrine secretion) and in cells that produce large amounts of membrane proteins (e.g. nerve cell with large membrane surface) (1). Molecules targeted to the endosomal-lysosomal pathway leave from the clathrin-coated, trans-most cisterna. Molecules for the apical and basolateral plasma membranes exit from the preceding trans-cisternae (27).

\section{The Functions of the Golgi Apparatus}

The Golgi complex is not only the core structure of the secretory pathway but is also essential to ensure lipid homeostasis, and plays a major role in signaling, autophagy, and apoptosis. As such it is involved in many human diseases and several Golgiassociated factors represent promising therapeutic targets (28).

The Role of the Golgi Apparatus in the Intracellular Transports and the Secretory Pathway: The secretory pathway through the ER to the plasma membrane includes the ER exit sites, the intermediate compartment (between the ER and the Golgi), the GA itself, the TGN, and several post-Golgi compartments. Since the GA is polarized, both morphologically and functionally bi-directional transport of the products is possible. In the course of anterograde transport, coated vesicles carry newly synthesized proteins from the GER to forming face of the GA. Traditionally, it has been accepted that newly synthesized proteins are transported from the GER to GA via COP-II coated vesicles (29). The exit sites of the ER appear as clusters of COP-II-coated buds, small 52-nm vesicles, and some tubules $(30,31)$. When the exit from the ER is blocked, the exit

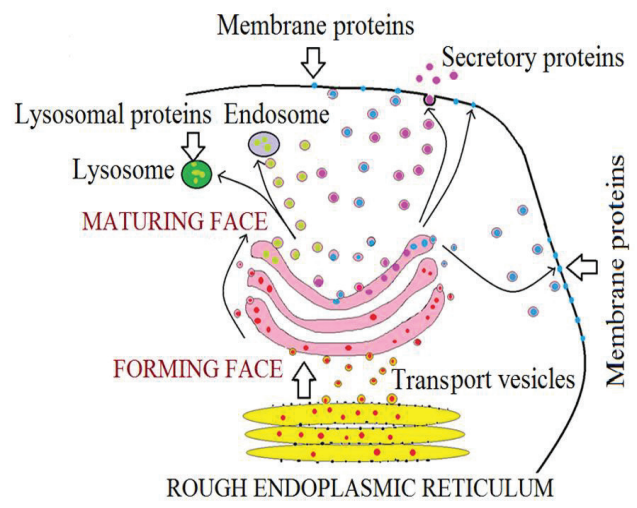

Figure 3. The sorting of the proteins from the Golgi apparatus is shown (drawn by the author herself) sites contain only one or two COP-II-coated buds. In contrast, the transporting exit sites contain more tubules and buds (30).

Ever since, a number of new data have added to the complexity of the transport events that take place at the ER-Golgi boundary. Currently, the two models for the GER to Golgi transport in mammalian cells are considered. One of those is the transport complex model. According to this model, from the ER exit sites, COP-II coated vesicles tether and fuse to form pleimorphic transport complexes, which in turn are transported along the microtubules. At the forming face of the GA transport complexes gather and undergo fusion. They may either fuse with the adjacent Golgi cisternae or alternatively form a new Golgi cisternae by homotyping fusion $(1,32)$. The second model is the stable compartment model which involves the anterograde membrane traffic through the ER-Golgi intermediate compartment (ERGIC) (intermediate organelle) (33). ERGIC is the tubulovesicular and vacuolar membrane clusters of the ERGIC (34). The basic difference between these models is that the former emphasizes the dynamic and transient character of this compartment, whereas the latter proposes that the membrane clusters defined by ERGIC-53 represent immobile, stable structures (35). Strikingly, recent results show that the ERGIC is composed of spatially and functionally distinct vacuolar and tubular domains that constitute a dynamic, but at the same time permanent, interconnected membrane system $(36,37)$. According to this model, short-range vesicular transport from the ER to the ERGIC depends on the transport of COP-II coated vesicles in a microtubule independent manner. However, long-range transport from the ERGIC to the forming face of the GA requires microtubules. Fission of anterograde carriers from the ERGIC may involve the COP-I coat, spectrin/anykrin skeleton.

According to the live cell imaging studies two types of mobile ERGIC carriers detach from the ER; one of those corresponds to the large-sized elements, which become elongated as they move, and the other corresponds to the narrow tubules, which bud from the more stationary, large ERGIC structures. The latter which are enriched in cargo proteins, the cargo receptor p58 and COP-I coats likely correspond to ERGIC vacuoles bound to the GA $(33,37)$. The microtubule dependent, longdistance movements of both types of carriers are often directed towards the cell center (35). The first marker protein of the ERGIC, ERGIC-53, functions as a mannose-binding cargo receptor in ER-Golgi trafficking and also involves microtubule dependent, long-distance movement of transport intermediates between widespread transitional ER sites [also called ER exit sites (ERES)] and the Golgi region $(34,38)$. Part of the tubules move in the opposite direction, fusing with or interconnecting nearby, more stationary ERGIC elements, thus creating a dynamic network $(36,37)$. In addition, some of the tubules move towards the cell periphery and establish a Golgi bypass pathway between the ERGIC and the cell cortex (35). It has been shown that the centrally located elements of the ERGIC communicate with the endolysosomal system, so such a connection might play an important role in the transport pathway by allowing newly made molecules to bypass the GA on their way for exocytosis (36). 
The initial capture or tethering of transport vesicles at the cisface of the GA is most likely mediated by golgins, a family of elongated coiled-coil tethering proteins. Golgins are anchored to the Golgi membrane via their carboxy terminus (39). Because of their coiled-coil nature, golgins are thought to extend a considerable distance (predicted to be in the range of 100-600 $\mathrm{nm}$ ) into the surrounding cytoplasm which is ideal for capturing vesicles at long range. Different types of golgins are localized in different Golgi regions. For instance, the golgins at the cis-Golgi capture ER- and ERGIC derived vesicles, golgins localized to cisternal rims capture intra-Golgi transport vesicles, and transGolgi golgins capture endosome-derived carriers (40). Another scenario could be that they tether non-vesicle membranes, which may include Golgi cisternae, or tubular regions of the Golgi such as the TGN (trans-Golgi network), the fenestrated regions located between stacks within the Golgi ribbon, or tubular carriers that have been postulated to mediate intra-Golgi traffic (41). Giantin is able to promote linking of Golgi stacks within the ribbon, suggesting a possible role in membrane tethering that is required to maintain Golgi organization as opposed to vesicle traffic (42). Conversely, Rab binding is likely more important for the steps that follow capture, where the vesicle has to move closer to the target membrane to undergo docking and fusion Rab2 binding acts downstream of tethering (40). Interaction between the vesicle-bound Rab and Golgi-membrane associated golgins could allow the vesicle to hop down the length of a golgin, or even onto an adjacent golgin able to bind the same Rab, helping it navigate its way through the meshwork of golgin "tentacles" to contact the Golgi membrane (7). Following entry to the Golgi system, the transport vesicles bud off dilated ends of the Golgi cisternea mediate transport between the adjacent cisternae. Conserved oligomeric Golgi (COG) is a complex comprised of eight subunits that is present on all Golgi cisternae and functions in intra-Golgi trafficking (43). They are shorter than the golgins, which suggests they would be less efficient at vesicle capture over long distance. In fact both COG and [Golgi-associated retrograde protein (GARP)] are well known to facilitate the transition from tethering to fusion. By interacting with components on both the vesicle and the target membrane, and by acting in conjunction with golgins, both the fidelity of vesicle recognition and the strength of vesicle attachment to the target membrane are likely greatly enhanced by COG and GARP (40). Retrograde transport (for re-processing of any inadequately or insufficiently modified, sorted/packaged product) from the forming face of the GA to GER as well retrograte transport between adjacent Golgi cisternae is mediated by COP-I coated vesicles $(1,44)$. The GA is embedded in a network of microtubules carrying the vesicles $(1,25)$. COP-I vesicles have been proposed to recycle resident Golgi enzymes, thereby keeping these enzymes in the organelle during cisternal maturation (45).

The ERGIC constitutes an independent structure that is not continuous with the ER or the cis-Golgi face. The ERGIC clusters are mobile transport complexes that deliver cargo from the GER membranes to the forming face of the Golgi. Traditionally, it has been accepted that newly synthesized proteins are transported from the GER to GA via COP-II coated vesicles. In summary, transport from the GER to the ERGIC is controlled by COPII, and subsequent sorting in the ERGIC involves COP-I (1). COPI-dependent vesicles are too small for the transport of large cargo aggregates, the size of which is greater than the size of the lumen of these vesicles (e.g.; chylomicron) (46). COP-I coated vesicles also play a well-established role in retrograde traffic from both the ERGIC and GA. The ERGIC, apart from the trafficking of the proteins, also contributes the concentration, folding, and quality control of newly synthesized proteins.

The role of the Golgi Apparatus in the Sorting Mechanism: Both anterograde and retrograde transport are mediated by the processes of budding and fusing of the vesicles between the Golgi cisternae. Namely, the vesicle bud from one cisterna fuses with the adjacent cisternae. So the continuity of membrane systems of the adjacent cisternae does not seem to be necassery (1). However, in different types of cells intercisternal heterogenous connections have been described (47). Even in some cells the GA forms a single continuous membranous system (but not in the resting stacks) $(48,49)$. The number of intercisternal connections increases after the arrival of cargo at the Golgi cisternae (41). These connections containing soluble cargo proteins might be involved in rapid transport through the Golgi cistarnea (50). Not only proteins but also lipids travel through the Golgi cisternae. They undergo a series of post-translational modifications during this journey. The tubulovesicular array of the maturing face of the GA serves as the sorting station for transporting vesicles that deliver proteins to the plasma membranes, to the apical region of the cell cytoplasm (of secretory cells) where proteins are stored in secretory vesicles, and to the endosomes and lysosomes (Figure 4). The actual sorting of proteins in the maturing face of the GA is primarily based on sorting signals. Most proteins destined for organelles bear specific signal sequences (sorting signals). For instance, mannose-6-phosphate (M-6-P) is attached to the surface of the inactive precursors of lysosomal enzymes (which are prohydrolases) which are destined to travel to late endosomes and lysosomes as recognition signal (1). The majority of soluble acid hydrolases are modified with M-6-P residues, allowing their recognition by M-6-P receptors in the Golgi complex and ensuring their transport to the endosomal/lysosomal system.

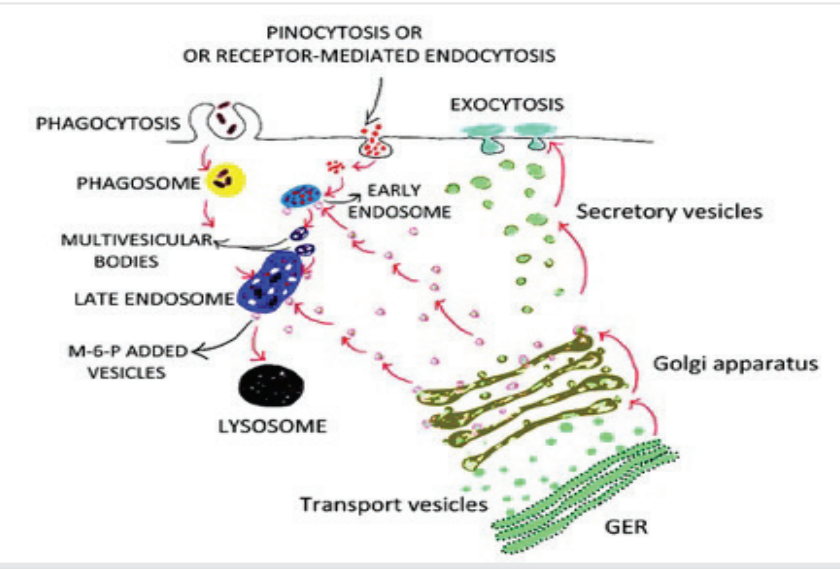

Figure 4. The Golgi apparatus and vesicular trafficking are shown (drawn by the author herself) 
M-6-P marker is generetad on specific N-linked oligosaccharides of the glycosylated lysosomal hydrolases in the secretory pathway. Next, the modified proteins are recognized by two independent receptors that bind the M-6-P residue of the newly synthesized lysosomal hydrolases in the trans-Golgi network. Finally, the ligand-receptor complex is packaged into clathrin coated transport vesicles for delivery to endosomes and lysosomes (51). M-6-P receptors are present in early and late endosomes, lysosomes (destination area) and GA (for transport between the Golgi sacs). Once anchored in the $\mathrm{N}$-linked oligosaccharides of newly synthesized hydrolases, the M-6-P recognition marker has to be recognized by specific receptors, so that the labeled hydrolases are correctly transported to the lysosome (52). M-6-P receptors, which are type I transmembrane glycoproteins that bind their specific oligosaccharide at $\mathrm{pH} 6,5-6,7$, in the transGolgi network and release it at $\mathrm{pH} 6$, the typical $\mathrm{pH}$ inside late endosomes. Inside these compartments, lysosomal hydrolases dissociate from the M-6-P receptors, and when the $\mathrm{pH}$ reaches 5 (the typical acidic $\mathrm{pH}$ of lysosomes which is maintained by a membrane ATP-driven $\mathrm{H}+$ pump), hydrolases begin to digest the endocytosed material delivered from early endosomes (53). Although M-6-P receptors play a major role in the intracellular transport of newly synthesized lysosomal enzymes in mammalian cells, several lines of evidence suggest the existence of alternative processes of lysosomal targeting. Among them, the two that are mediated by the M-6-P alternative receptors, lysosomal integral membrane protein (LIMP-2) and sortilin, have gained unequivocal support. There are soluble enzymes as well as nonenzymatic proteins that are transported to lysosomes in a M-6-P independent manner (54) (Coutinha, Alves 2012). LIMP-2 transports glucocerebrosidase to the lysosomes. On the other hand, sortilin which is multifunctional protein was proposed to be responsible for the lysosomal transport of some enzymes including sphingomyelinase and cathepsins $\mathrm{D}$ and $\mathrm{H}$ (5557). Like M-6-P receptors, sortilin is thought to be an ancient receptor involved in a conserved trafficking mechanism (55). The sorting mechanism sometimes is not perfect, so for instance proteins destined for lysosomes may travel directly to and incorporated into the plasma membrane. These proteins then move back into the endosomal pathway (into early endosomes, to late endosomes and then to lysosomes, as expected) (1). The presence of clathrin-coated buds and tubules on only the trans-most cisterna of the Golgi indicates a unique exit site for cargo destined for the endosomal-lysosomal pathway (53). In contrast, buds and tubules arising from the other trans-cisternae are either nonclathrin-coated or uncoated (27). Long ago, it has been suggested that that newly synthesized lysosomal enzymes bypassed Golgi cisternae and were delivered directly from the ER to the trans-most cisterna, whereas secretory proteins exited the Golgi from the penultimate transcisterna (58).

In summary, the main function of the GA is to modify, sort and package the macromolecules synthesized for secretion or for internal utilization. The Golgi complex has the ability to modify proteins by adding carbonhydrates (thus produce glycoproteins and proteoglycans) and phosphate by the process of glycosylation and phoshphorylation respectively (1). The glycosylation enzymes that reside in the Golgi cisternae and are involved in the early stages of glycosylation are located mostly at the cisside. Conversely, the late and terminal glycosylation enzymes are situated at the trans-side of the Golgi stacks (59). Additionally, it also involves in the sulfation of some molecules. In fact; it also creates lysosomes by releasing targeted lysosomal enzymes.

The Role of the Golgi Apparatus in $\mathbf{C a}^{2+}$ Store: In the last decade, it became clear that the GA also play an important role as an intracellular $\mathrm{Ca}^{2+}$ store behaving similarly to the main intracellular $\mathrm{Ca}^{2+}$ store that is SER. The GA is thus equipped with all the molecular components necessary for its function as a $\mathrm{Ca}^{2+}$ store: $\mathrm{Ca}^{2+}$ pumps, $\mathrm{Ca}^{2+}$ channels and luminal $\mathrm{Ca}^{2+}$ binding proteins (60). Chandra et al. (61) showed that the GA can store up to $5 \%$ of the total cellular $\mathrm{Ca}^{2+}$ and that it is substantially more resistant to $\mathrm{Ca}^{2+}$ depletion than other cellular organelles. The recent similar evidences showed that the latencies and initial rates of $\mathrm{Ca}^{2+}$ release from the GA and the ER were similar. However, $\mathrm{Ca}^{2+}$ release from the GA terminated faster resulting in a smaller extent of $\mathrm{Ca}^{2+}$ release. Fast reuptake of released $\mathrm{Ca}^{2+}$ by the GA may underlie fast termination of $\mathrm{Ca}^{2+}$ release from this compartment. It is clear that both the GA and the ER release $\mathrm{Ca}^{2+}$ during the generation of cytosolic $\mathrm{Ca}^{2+}$ signals, but the timecourses of the $\mathrm{Ca}^{2+}$ release are different (62). Luminal $\mathrm{Ca}^{2+}$ within the GA might be fundamental in controlling some key processes of the organelle including post-translational modifications, protein sorting and trafficking. The activity of the enzymes located in the GA and trans Golgi network, retrograde membrane traffic from the Golgi to the ER and selective aggregation of regulated secretory proteins in the trans Golgi network seem to be critically dependent on GA Ca ${ }^{2+}$ content $(63,64)$. Therefore, luminal concentration changes of the $\mathrm{Ca}^{2+}$ within the GA could affect several cellular functions. Moreover, selective reduction of $\mathrm{Ca}^{2+}$ concentration within trans-Golgi compartment results in major alterations of protein trafficking and induces the collapse of the entire GA morphology (65).

The Role of the Golgi Apparatus in Microtubule Nucleation: In recent years, the GA has emerged as a site that can nucleate and stabilize the microtubules $(66,67)$. Traditionally it has been accepted that the microtubule organizing centers which are centrosomes, basal bodies and centromers of the chromosomes are responsible for the microtubule nucleation, stabilization and organization (1). The microtubules derived from the GA participate in Golgi assembly when the cell division is completed. Golgi-derived microtubules participate in Golgi reassembly after cell division by promoting fusion of the Golgi stacks into the Golgi ribbon (67). Furthermore, unlike centrosomal microtubules, Golgi-anchored micrtobule arrays are polarized and can thus promote cell asymmetry and polarized transport of post-Golgi carriers that are important for cell migration (68). Interestingly, in differentiated cells, the membranes of the GA are suggested to serve as microtubule organizing centers controlling the formation of non-centrosomal microtubule arrays, which are for cell morphogenesis and function. A good example of this kind of function of the GA is neurite outgrowth and branching in neuronal cells (69). 


\section{Conclusion}

As a conclusion, I emphasize that:

- The GA is not composed of a simple discontinuous parallel stacks but is composed of various domains including cis-Golgi network, trans-Golgi network, intercisternal network, ERGIC (we may consider that as a part of the Golgi), various coated vesicles, vacuoles and tubules,

- The GA is not only involved in the secretory pathway, but also involved in the storage of $\mathrm{Ca}^{2+}$ very likely to smooth endoplasmic reticulum,

- The GA might serve as a microtubule organizing center which is especially important to participate in Golgi reassembly after cell division,

- The GA is not a stable organelle instead a highyl dynamic organelle changing its morphological and functional characteristics in different phyological and pathological conditions.

Peer-review: Externally peer-reviewed.

Financial Disclosure: The authors declared that this study received no financial support.

\section{References}

1. Esrefoglu M. The cell: A microscopic and functional approach. 1st ed. Berlin: Lambert Academic Publishing; 2018.

2. Boncompain G, Weigel AV. Transport and sorting in the Golgi complex: multiple mechanisms sort diverse cargo. Curr Opinion Cell Biol 2018;50:94-101.

3. Mellman I, Warren G. The road taken: past and future foundations of membrane traffic. Cell 2000;100:99-112.

4. Misteli T, Warren G. Mitotic disassembly of the Golgi apparatus in vivo. J Cell Sci 1995;108:2715-27.

5. Marra P, Salvatore L, Mironov A, Jr. Di Campli A, Di Tullio G, Trucco A, et al. The biogenesis of the Golgi ribbon: The roles of membrane input from the ER and of GM130. Mol Biol Cell 2007;18:1595-608.

6. Sütterlin C, Colanzi A. The Golgi and the centrosome: Building a functional partnership.

7. J Cell Biol 2010;188:621-8.

8. Munro S. The golgin coiled-coil proteins of the Golgi apparatus. Cold Spring Harb Perspect Biol 2011;3:a005256.

9. Lowe M. Structural organization of the Golgi apparatus. Curr Opin Cell Biol 2011;23:85-93.

10. Rios RM, Bornens M. The Golgi apparatus at the cell centre. Curr Opin Cell Biol 2003;15:60-6.

11. Colanzi A, Süterlin C. Signaling at the Golgi During Mitosis. Methods Cell Biol 2013;118:383-400.

12. Papanikou E, Glick BS. The yeast Golgi apparatus: Insights and mysteries. FEBS Lett 2009;583:3746-51.

13. Xiang Y, Zhang X, Nix DB, Katoh T, Aoki K, Tiemeyer M, et al. Regulation of protein glycosylation and sorting by the Golgi matrix proteins GRASP55/65. Nat Comm 2013;4:1659.
14. Puthenveedu MA, Bachert C, Puri S, Lanni F, Linstedt AD. GM130 and GRASP65-dependent lateral cisternal fusion allows uniform Golgi-enzyme distribution. Nat Cell Biol 2006;8:238-48.

15. Kondylis V, Rabouille C. The Golgi apparatus: Lessons from Drosophila. FEBS Lett 2009;583:827-38.

16. Shorter J, Warren G. Golgi architecture and inheritance. Annu Rev Cell Dev Biol 2002;18:379-420.

17. De Matteis MA, Morrow JS. Spectrin tethers and mesh in the biosynthetic pathway. J Cell Sci 2000;113:2331-43.

18. Ward TH, Polishchuk RS, Caplan S, Hirschberg K, LippincottSchwartz J. Maintenance of Golgi structure and function depends on the integrity of ER export. J Cell Biol 2001;155:557-70.

19. Colanzi A, Hidalgo Carcedo C, Persico A, Cericola C, Turacchio G, Bonazzi $M$, et al. The Golgi mitotic checkpoint is controlled by BARS-dependent fission of the Golgi ribbon into separate stacks in G2. EMBO J 2007;26:2465-76.

20. Colanzi A, Suetterlin C, Malhotra V. Cell-cycle-specific Golgi fragmentation: How and why? Curr Opin Cell Biol 2003;15:462-7.

21. Gaietta GM, Giepmans BN, Deerinck TJ, Smith WB, Ngan L, Llopis $\mathrm{J}$, et al. Golgi twins in late mitosis revealed by genetically encoded tags for live cell imaging and correlated electron microscopy. Proc Natl Acad Sci USA 2006;103:17777-82.

22. Zhang X, Wang Y. GRASPs in Golgi structure and function. Front Cell Dev Biol 2016;3:1-8.

23. Mollenhauer HH, Morré DJ. Perspectives on Golgi apparatus form and function. J Electron Microsc Tech 1991;17:2-14.

24. Bonfanti L, Mironov AA Jr, Martínez-Menárguez JA, Martella O, Fusella A, Baldassarre M, et al. Procollagen traverses the Golgi stack without leaving the lumen of cisternae: evidence for cisternal maturation. Cell 1998;95:993-1003.

25. Presley JF, Cole NB, Schroer TA, Hirschberg K, Zaal KJ, LippincottSchwartz J. ER-to-Golgi transport visualized in living cells. Nature 1997;389:81-5.

26. Marsh BJ, Mastronarde DN, McIntosh JR, Howell KE. Structural evidence for multiple transport mechanisms through the Golgi in the pancreatic beta-cell line, HIT-T15. Biochem Soc Trans 2001;29:461-7.

27. Hauri HP, Schweizer A. The endoplasmic reticulum-Golgi intermediate compartment. Curr Opin Cell Biol 1992;4:600-8.

28. Mogelsvang S, Marsh BJ, Ladinsky MS, Howell KE. Predicting function from structure: 3D structure studies of the mammalian Golgi complex. Traffic 2004;5:338-45.

29. Zappa F, Failli M, De Matteis A. The Golgi complex in disease and therapy. Curr Opin Cell Biol 2018;50:102-16.

30. Hughes H, Stephens DJ. Assembly, organization, and function of the COPII coat. Histochem Cell Biol 2008;129:129-51.

31. Mironov AA, Mironov Jr AA, Beznoussenko GV, Trucco A, Lupetti P, Smith JD, et al. ER-to-Golgi carriers arise through direct en blocprotrusion and multistage maturation of specialized ER exit domains. Dev Cell 2003;5:583-94.

32. Bannykh SI, Rowe T, Balch WE. The organization of endoplasmicreticulum export complexes. J Cell Biol 1996;135:1935. 
33. Bannykh SI, Nishimura N, Balch WE. Getting into the Golgi. Trends Cell Biol 1998;8:21-5.

34. Saraste J, Kuismanen E. Pre- and post-Golgi vacuoles operate in the transport of Semliki Forest virus membrane glycoproteins to the cell surface. Cell 1984;38:535-49.

35. Herzog CA, Hauri FP. The ER-Golgi intermediate compartment (ERGIC): in search of its identity and function. J Cell Sci 2006;119:2173-83.

36. Saraste J Dale HA, Bazzocco S, Marie M. Emerging new roles of the pre-Golgi intermediate compartment in biosynthetic-secretory trafficking. FEBS Lett 2009;583:3804-10.

37. Marie M, Dale HA, Sannerud R, Saraste J. The function of the intermediate compartment in pre-Golgi trafficking involves its stable connection with the centrosome. Mol Biol Cell 2009;20:4458-70.

38. Sannerud R, Marie M, Nizak C, Dale HA, Pernet-Gallay K, Perez $\mathrm{F}$, et al. Rab1 defines a novel pathway connecting the pre- Golgi intermediate compartment with the cell periphery. Mol Biol Cell 2006;17:1514-26.

39. Palmer KJ, Watson P, Stephens DJ. The role of microtubules in transport between the endoplasmic reticulum and Golgi apparatus in mammalian cells. Biochem Soc Symp 2005;72:1-13.

40. Gillingham AK, Munro S. Finding the Golgi: golgin coiled-coil proteins show the way. Trends Cell Biol 2016;26:399-408.

41. Witkos TM, Lowe M. Recognition and tethering of transport vesicles at the Golgi apparatus. Curr Opin Cell Biol 2017;47:16-23.

42. Trucco A, Polishchuk RS, Martella O, Di Pentima A, Fusella A, DiGiandomenico D, et al. Secretory traffic triggers the formation of tubularcontinuities across Golgi sub-compartments. Nat Cell Biol 2004;6:1071-81.

43. Koreishi M, Gniadek TJ, Yu S, Masuda J, Honjo Y, Satoh A. The golgin tether giantin regulates the secretory pathway by controlling stack organization within Golgi apparatus. PLoS One 2013;8:e59821.

44. Willett R, Ungar D, Lupashin V. The Golgi puppet master: COG complex at center stage of membrane trafficking interactions. Histochem Cell Biol 2013;140:271-83.

45. Béthune J, Wieland F, Moelleken J. COPI-mediated transport. J Membr Biol 2006;211:65-79.

46. Glick BS, Elston T, Oster G. A cisternal maturation mechanism can explain the asymmetry of the Golgi stack. FEBS Lett 1997;414:17781.

47. Sabesin SM, Frase S. Electron microscopic studies of the assembly,intracellular transport, and secretion of chylomicrons by rat intestine. J Lipid Res 1977;18:496-511.

48. Mironov AA, Sesorova IS, Seliverstova EV, Beznoussenko GV. Different Golgi ultrastructure across species and tissues: Implications under functional and pathological conditions, and an attempt at classification. Tissue Cell 2017;49:186-201.

49. Tanaka K, Mitsushima A, Fukudome H, Kashima Y. Threedimensional architecture of the Golgi complex observed by high resolution scanning electron microscopy. J Submicrosc Cytol 1986;18:1-9.
50. Rambourg A, Clermont Y. Three-dimensional structure of the Golgi apparatus in mammalian cells. In: Roth J, Berger EG, editors. The Golgi Apparatus. Basel: Birkhauser; 1997.pp.37-611.

51. Nakano A, Luini A. Passage through the Golgi. Curr Opin Cell Biol 2010;22:471-78.

52. Braulke T, Bonifacino JS. Sorting of lysosomal proteins. Biochim Biophys Acta 2009;1793:605-14.

53. Alberts B, Johnson A, Lewis J, Raff M, Roberts K, Walter P. Molecular biology of the cell. 4th ed. New York: Garland Science. 2002.

54. Kornfeld S, Mellman I. The biogenesis of lysosomes. Annu Rev Cell Biol 1989;5:483-525.

55. Coutinho MF, Prata MJ, Alves S. A shortcut to the lysosome: The mannose-6-phosphate-independent pathway. Mol Genet Metab 2012;107:257-66

56. Ni X, Canuel M, Morales CR. The sorting and trafficking of lysosomal proteins. Histol Histopathol 2006;21:899-913.

57. Lefrancois S, Zeng J, Hassan AJ, Canuel M, Morales CR. The lysosomal trafficking of sphingolipid activator proteins (SAPs) is mediated by sortilin. EMBO J 2003;22:6430-7.

58. Canuel M, Korkidakis A, Konnyu K, Morales CR. Sortilin mediates the lysosomal targeting of cathepsins D and H. Biochem Biophys Res Commun 2008;373:292-7.

59. Novikoff PM, Novikoff AB, Quintana N, Hauw JJ. Golgi apparatus, GERL, and lysosomes of neurons in rat dorsal root ganglia, studied by thick section and thin section cytochemistry. J Cell Biol 1971;50:859-86.

60. Rabouille C, Hui N, Hunte F, Kieckbusch R, Berger EG, Warren $\mathrm{G}$, et al. Mapping the distribution of Golgi enzymes involved in the constructionof complex oligosaccharides. J Cell Sci 1995;108:161727.

61. Pizzo P, Lissandron V, Capitanio P, Pozzan T. Ca2+ signalling in the Golgi apparatus. Cell Calcium 2011;50:184-92.

62. Chandra S, Kable EP, Morrison GH, Webb WW. Calcium sequestration in the Golgi apparatus of cultured mammalian cells revealed by laser scanning confocal microscopy and ion microscopy. J Cell Sci 1991;100:747-52.

63. Missiaen L, Van Acker K, Van Baelen K, Raeymaekers L, Wuytack F, Parys JB, et al. Calcium release from the Golgi apparatus and the endoplasmic reticulum in HeLa cells stably expressing targeted aequorin to these compartments. Cell Calcium 2004;36:479-87.

64. Carnell L, Moore HP. Transport via the regulated secretory pathway in semiintact PC1 2 cells: role of intra-cisternal calcium and $\mathrm{pH}$ in the transport and sorting of secretogranin II. J Cell Biol 1994;127:693705 .

65. Ivessa NE, De Lemos-Chiarandini C, Gravotta D, Sabatini DD, Kreibich G. The Brefeldin A-induced retrograde transport from the Golgi apparatus to the endoplasmic reticulum depends on calcium sequestered to intracellular stores. J Biol Chem 1995;270:25960-7.

66. Pizzo P, Lissandron V, Pozzan T. The trans-golgi compartment: A new distinct intracellular Ca store. Commun Integr Biol 2010;3:462-4. 
67. Sanders AA, Kaverina I. Nucleation and dynamics of Golgi derived microtubules. Front Neurosci 2015;9:431.

68. Zhu X, Kaverina I. Golgi as an MTOC: making microtubules for its own good. Histochem Cell Biol 2013;140:361-7.

69. Hurtado L, Caballero C, Gavilan MP, Cardenas J, Bornen, M, Rios RM. Disconnecting the Golgi ribbon from the centrosome prevents directional cell migration and ciliogenesis. J Cell Biol 2011;193:91733.

70. Ori-McKenney KM, Jan LY, Jan YN. Golgi outposts shape dendrite morphology by functioning as sites of acentrosomal microtubule nucleation in neurons. Neuron 2012;76:921-30. 